\title{
Correction to: Data Ethics in Epidemiology: Autonomy, Privacy, Confidentiality and Justice
}

Vijayaprasad Gopichandran and Varalakshmi Elango

\section{Correction to:}

Chapter 7 in: A. Mishra, K. Subbiah (eds.), Ethics in Public Health Practice in India, https://doi.org/10.1007/978-981-13-2450-5_7

The original version of Chapter 7 was inadvertently published with incorrect surname of the second author. The surname of the second author was presented incorrectly as Elang. The correct surname of the second author should read Elango.

The chapter has been updated. 